\title{
Sepsis Following Laparotomy for Trauma - Don't Watch and Wait
}

\author{
Piers R.J. Page*
}

\section{INTRODUCTION}

Exploratory laparotomy is one of the most frequently performed surgical procedures in the trauma setting, usually in the context of emergency surgery when abdominal injury has been demonstrated by appearance of free fluid on imaging. It has, for reasons yet to be fully understood, a comparatively high rate of infection, and this case demonstrates the potentially fatal course of such a complication left untreated.

\section{CASE REPORT}

EA, a 17 year old Hispanic male, was found facedown in a Washington DC park with multiple gunshot wounds. On arrival at the trauma facility, it was established that he had been shot in the left cheek, right shoulder and left flank, with extensive overt facial and thoracic injuries. As is dictated by protocol in these situations, a Focused Abdominal Sonogram for Trauma (FAST) was performed, revealing free fluid in the abdomen. This, in combination with haemodynamic instability, indicated a requirement for surgery, and so he was taken to the OR for exploratory laparotomy.

Damage was found to the spleen, liver, stomach and diaphragm, and the spleen was removed at this point. The abdomen was then packed and covered with a vacuum dressing, and the patient sent to SICU. On day 2 post-injury, he was taken back to the OR for closure of his abdominal wound. Once this was complete, the oromaxillofacial surgery team took him straight over on the table for reduction and fixation of his facial fractures, achieved with Lorenz plates and monocortical screws. He was then returned, still intubated, to the SICU.

On day 6 , he developed an infection and fever, with

* To whom correspondance should be addressed: Piers R.J. Page, University of Newcastle upon Tyne, Framlington Place, Newcastle upon Tyne, NE2 4HH

Email: piers.page@ncl.ac.uk marked leucocytosis, and on day 7 an area of periumbilical purulence was noted, from which several sutures were removed. On day 8, break evisceration occurred, and total fascial dehiscence with the appearance of necrotizing fasciitis was noted in the OR. Emergency debridement was performed over the next three days, with the decision taken to leave a ventral hernia for definitive closure at a much later date. A split-thickness skin graft was placed into the abdominal wound, and the patient was eventually discharged from hospital some 4 weeks later, to be reviewed later in the year for abdominal closure.

\section{DISCUSSION}

So what should we have done differently? EA's situation probably arose from a number of decisions, no single one of which can be deemed solely responsible. The first major decision with potential involvement was early closure of the abdominal wall. The natures of the injuries sustained by the patient were suggestive of potential abdominal contamination; gastric lacerations spilling stomach contents from the time of injury, followed by laparotomy on a full bowel. With hindsight, EA was definitely a candidate for delayed primary closure, which would have simply involved continuation with the vacuum dressing already in use between initial operation and closure. These devices have been proven [1] to provide sufficient medial traction of the abdominal layers to reduce elective ventral herniation rates, even in patients requiring multiple laparotomies. Another technique, described by Jernigan et al [2], is the use of absorbable polyglactin mesh, which can have pleats drawn in it at the bedside to gradually draw the wound edges together.

The main pointer against definitive early closure was his white cell count, which had climbed to 11,000 by early morning on day 2 , from 4,300 after his initial 
Table 1. EA's White Cell Counts during early stages of treatment

\begin{tabular}{|l|l|l|l|}
\hline \hline Day & Time & Count $(\mathbf{K} / \mathbf{u l})$ & Remarks \\
\hline 0 & 0545 & 7.9 & Initial surgery \\
\hline 0 & 1045 & 4.3 & \\
\hline 1 & 0500 & 11.0 & \\
\hline 2 & 0439 & 13.4 & \\
\hline 2 & 1915 & 10.7 & Abdomen closed \& facial fxs repaired \\
\hline 3 & & & \\
\hline 4 & 0500 & 11.4 & \\
\hline 5 & 0500 & 13.4 & Purulence noted, local sutures removed \\
\hline 7 & 0500 & 15.5 & Evisceration \& re-operation \\
\hline 8 & 0530 & 21.8 & \\
\hline
\end{tabular}

surgery. Even allowing for the body's inflammatory response to trauma surgery [3], it may well have been wise to have taken heed of this result and forestalled on closure to monitor the situation.

Having committed to closing the abdomen, close surveillance should have been in place for any signs of infection, with a very low index of suspicion for acting on them. Serial blood counts were taken daily (see Table 1 and Figure 1) except, crucially, on day 6. Between the mornings of days 5 and 7, the white cell count rose from 15,500 to 21,800 , and a further rise to 25,600 preceded dehiscence on day 8 . These counts were all recorded in the notes, and seem to have been dismissed as they were rising only small amounts relative to the previous counts. Shown in context of the counts over the entire admission, of course, they should have set alarm bells ringing, especially given that the steady climb began after definitive closure.

The patient's persistent pyrexia should also have been considered in the wider context. He was treated for his sepsis with appropriate antibiotic and fluid therapy, but this does not, of course, address the initial source of the infection; in a patient with a newly closed abdomen, the first suspicion should always be intraabdominal. In combination with the medical notes documenting localized tenderness and erythema around the wound (which are, of course, criteria for sepsis), there should have been little doubt that EA

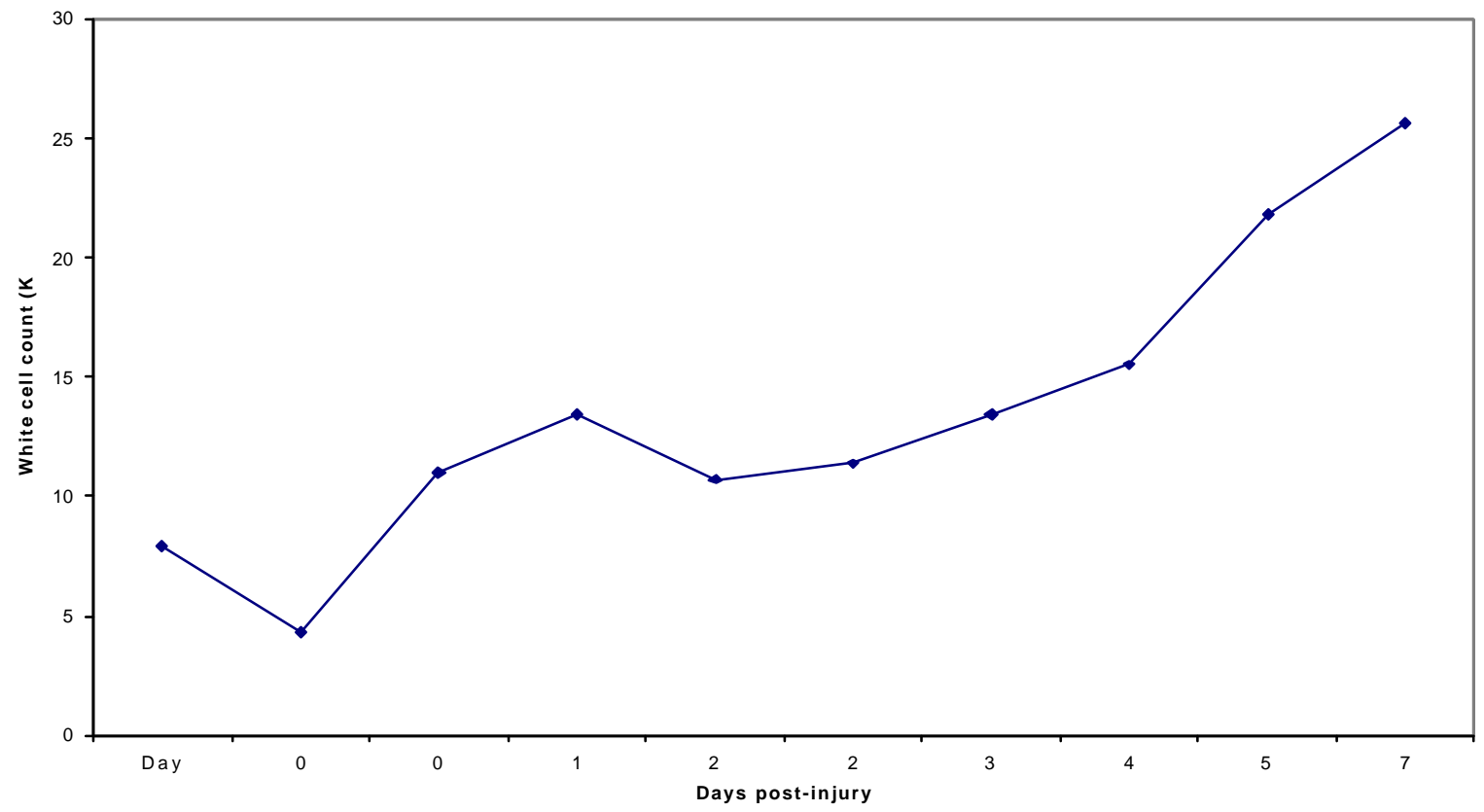

Figure 1. EA's White Cell Counts during early stages of treatment 
needed urgent re-operation.

Are clinical signs alone enough justification for reoperation? In this age of readily available imaging studies, many would argue for obtaining at least a CT before taking the patient to the OR again. Studies have shown consistently, however, that there is an overall benefit from re-operation justified solely by clinical impression. In Hinsdale and Jaffe's work [4] in the mid 1980 s, for example, it was found that clinical signs were at least as reliable as high-tech (for the time) imaging; of special note should be the benefits of early surgery when a patient appears to be entering multiple organ failure. Interestingly, in a later bout of infection not related to this incident, the patient had a negative CT scan but exhibited very definite clinical signs, caused by an abscess only discernible on repeat CT 48 hours later; anecdotal reinforcement of the evidence discussed here.

Tillou et al [5] found that $71 \%$ of patients, albeit in a small study $(\mathrm{n}=55)$, with fascial dehiscence had underlying intra-abdominal infection, and hence essentially that localized wound infection was likely to be the tip of the iceberg. Velmahos' review [6] of the evidence suggested re-laparotomy every 24-48 hours until sepsis is eradicated is still a lower risk method of management than either waiting for evolution of the situation or radiological confirmation. Recent work in America [7] found that laparotomy was becoming a more frequent intervention, as was delayed primary closure, which had a higher morbidity but overall improved survival rates.

In summary, a bad situation worsened through lack of decision making. The following points are salient in all cases:
- Never consider signs, symptoms or lab results in isolation. Look for the trend - there is very often an obvious pattern to be found

- A clinical picture of postoperative deterioration should not be left to evolve in the hope it will resolve or the cause will become more obvious

- In patients with a wound which is an obvious first choice for focus of infection, there should be a low threshold for decision to re-explore

- Only delay for imaging if the resulting information may substantially change management.

\section{REFERENCES}

1. Miller PR, Meredith JW, Chang MC. Prospective evaluation of vacuum-assisted fascial closure after open abdomen: planned ventral hernia rate is substantially reduced. Annals of Surgery 239(5):608-14; 2004

2. Jernigan TW, Fabian TC, Croce MA, et al. Staged management of giant abdominal wall defects: acute and long-term results. Annals of Surgery 238(3):349-55; 2003

3. Kalff JC, Turler A, Schwarz NT, et al. Intra-abdominal of activation of a local inflammatory response within the human muscularis externa during laparotomy. Annals of Surgery. 237(3):301-15; 2003

4. Hinsdale JG, Jaffe BM. Re-operation for intra-abdominal sepsis. Indications and results in a modern critical care setting. Annals of Surgery 199(1)31-6; 1984

5. Tillou A, Weng J, Alkousakis T, Velmahos G. Fascial dehiscence after trauma laparotomy: a sign of intra-abdominal sepsis. American Surgeon 69(11):927-9; 2003

6. Velmahos GC, Degiannis E, Souter I. Relaparotomies for abdominal sepsis--why, when how? A collective review. South African Journal of Surgery 36(2):52-6; 1998

7. Nicholas JM, Rix EP, Easley KA, et al. Changing patterns in the management of penetrating abdominal trauma: the more things change, the more they stay the same. Journal of Trauma, Injury, Infection and Critical Care. 55(6):1095-1110; 2003

Piers Page is a final year medical student at University of Newcastle upon Tyne, UK. He has specialist interest in military medicine, prehospital and trauma care. 